sensitivity and specificity for IgG, 15-21 days after symptoms onset are $96.2 \%$ and $96.6 \%$, respectively. Blood specimens were drawn from 2 weeks after the specified period commencing May 14, 2020, and ending May 19, 2020.

\section{Results}

Overall, 134 ICU HCP responded to the survey: 75\% were women, $47.73 \%$ were registered nurses, $9.85 \%$ were attending physicians, $26.52 \%$ were resident physicians, $6.82 \%$ were patient care assistants, $6.82 \%$ were respiratory therapists, $1.52 \%$ were technicians, and $0.76 \%$ were anesthetists. The mean age of the respondents was 39.2 years (IQR, 28-48.5). The mean duration of work was 29.3 days (IQR, 16.0-40.0). Of 134 ICU HCP eligible staff, 13 were excluded and 121 underwent SARS-CoV-2-specific IgG antibody testing. One individual tested positive and 1 test result was inconclusive due to a faulty test kit and was removed from the analysis. In this study, the prevalence of asymptomatic seroconversion was $0.83 \%$.

\section{Discussion}

Information about the prevalence of asymptomatic seroconversion of SARS-CoV-2 in HCP is limited. In a preliminary report released by the Centers for Disease Control and Prevention (CDC), nearly 9,282 HCP have contracted COVID-19, and 27 have died. ${ }^{3}$ Okba et $\mathrm{al}^{4}$ demonstrated that most PCR-confirmed SARS-CoV-2 patients seroconverted after 2 weeks of disease onset. ${ }^{4}$ Our study revealed a prevalence of $0.83 \%$, which indicates that seroconversion in ICU HCP was a rare event. These data indicate that proper education and utilization of personal protective equipment (PPE) is effective. ${ }^{5}$ Additionally, ventilated patients have less aerosolization and were housed in a negative-pressure environment in the ICU isolation rooms, which also may have been factors in avoiding transmission to HCP.
Our study has several limitations. It was conducted in a single-center ICU and did not include long-term clinical or laboratory follow-up. Studies with larger sample sizes in different healthcare settings would be useful to validate the clinical impact of our findings.

Acknowledgments. We acknowledge Dr Violet E Kramer MD and Dr Margaret $\mathrm{H}$ Eng $\mathrm{MD}$ for their assistance. We acknowledge Joann Wolfson DNP, MSN, CCRN, with critical care services and Joseph Jaeger, $\mathrm{DrPH}$, chief academic officer, as well as Ali Jaffery, for contributing to data collection. We acknowledge Barbara Mihelic for institutional review board support at Monmouth Medical Center, Long Branch, New Jersey.

Financial support. No financial support was provided relevant to this article.

Conflicts of interest. All authors report no conflicts of interest relevant to this article.

\section{References}

1. Tran K, Cimon K, Severn M, Pessoa-Silva CL, Conly J. Aerosol-generating procedures and risk of transmission of acute respiratory infections to healthcare workers: a systematic review. PLoS One 2012;7(4):e35797. doi: 10.1371/ journal.pone.0035797.

2. Sood N, Simon P, Ebner P, et al. Seroprevalence of SARS-Cov-2-specific antibodies among adults in Los Angeles County, California, on April 10-11, 2020. JAMA 2020. https://doi.org/10.1001/jama.2020.8279.

3. Burrer SL, De Perio MA, Hughes, MM, et al. Characteristics of healthcare personnel with COVID-19-United States, February 12-April 9, 2020. Morbid Mortal Wkly Rept 2020;69:477-481.

4. Okba NM, Müller MA, Li W, et al. Severe acute respiratory syndrome coronavirus 2-specific antibody responses in coronavirus disease 2019 patients. Emerg Infect Dis 2020;6(7). doi: 10.3201/eid2607. 200841.

5. Seto W, Tsang D, Yung R, et al. Effectiveness of precautions against droplets and contact in prevention of nosocomial transmission of severe acute respiratory syndrome (SARS). Lancet 2003;361:1519-1520.

\title{
A framework for nosocomial transmission of emerging coronaviruses
}

\author{
Seth D. Judson $\mathrm{MD}^{1}$ and Vincent J. Munster $\mathrm{PhD}^{2}$ (1) \\ ${ }^{1}$ Department of Medicine, University of Washington, Seattle, Washington and ${ }^{2}$ Laboratory of Virology, Division of Intramural Research, National Institute of \\ Allergy and Infectious Diseases, National Institutes of Health, Hamilton, Montana
}

To the Editor-Over the past 17 years, 3 coronaviruses have emerged and caused diseases with high case fatality rates. From the severe acute respiratory syndrome (SARS) epidemic of 2002-2003, to outbreaks of Middle East respiratory syndrome (MERS) since 2013, to the pandemic of coronavirus disease 2019 (COVID-19), coronavirus diseases have afflicted global communities. Nosocomial, or healthcare-associated infections, have been recognized with each of these diseases because the viruses that cause these diseases are contagious, are relatively stable on surfaces, and are potentially disseminated through medical procedures.

\footnotetext{
Author for correspondence: Vincent J. Munster, E-mail: munstervj@niaid.nih.gov Cite this article: Judson SD and Munster VJ. (2021). A framework for nosocomial transmission of emerging coronaviruses. Infection Control \& Hospital Epidemiology, 42: 639-641, https://doi.org/10.1017/ice.2020.296
}

With the emergence of severe acute respiratory syndrome coronavirus 2 (SARS-CoV-2), the virus that causes COVID-19, many have wondered whether personal protective equipment (PPE) and hospital protocols are adequate to prevent transmission. To answer these questions, it is helpful to examine prior data for severe acute respiratory syndrome coronavirus 1 (SARS-CoV-1) and Middle East respiratory syndrome coronavirus (MERS-CoV).

Transmission of a virus occurs when an individual sheds viable virus that infects a susceptible host either through direct contact, through indirect contact with a contaminated surface (fomite transmission), or by exposure to virus-laden particles suspended in air. These particles are aerosols, which are often divided by size into large and small droplets. ${ }^{1}$ The term droplet transmission refers to infection via large droplets, and airborne transmission refers to 
Table 1. Characteristics of Emerging Coronaviruses and Nosocomial Transmission

\begin{tabular}{|c|c|c|c|c|c|}
\hline Virus & $\begin{array}{l}\text { Location of } \\
\text { Shedding }\end{array}$ & Stability & Receptor & $\begin{array}{l}\text { Cases Among HCWs, } \\
\text { No }(\%)\end{array}$ & Associated Settings/Procedures \\
\hline SARS-CoV-1 & $\begin{array}{l}\text { URT }^{3} \\
\text { LRT }^{3} \\
\text { Urine } \\
\text { Feces }^{3}\end{array}$ & $\begin{array}{l}\text { Similarly stable in aerosol } \\
\text { as SARS-CoV- } 2^{9}\end{array}$ & ACE-2 & $\begin{array}{l}10,002(18.8) \text { China } 2003^{2} \\
386(22) \text { Hong Kong } 2003^{2} \\
97(40.8) \text { Singapore } 2003^{2} \\
36(57.1) \text { Vietnam } 2003^{2} \\
109(43.4) \text { Canada } 2003^{2}\end{array}$ & $\begin{array}{l}\text { Settings: hospital } \\
\text { Procedures: CPR, bronchoscopy, noninvasive } \\
\text { ventilation, intubation, manual ventilation }{ }^{1}\end{array}$ \\
\hline MERS-CoV & $\begin{array}{l}\text { URT }^{5} \\
\text { LRT }^{5} \\
\text { Urine } \\
\text { Feces } \\
\text { Fece }^{5, a}\end{array}$ & $\begin{array}{l}\text { More stable on surfaces at } \\
\text { temperate than tropical } \\
\text { conditions }{ }^{4} \\
\text { Decreased stability in aerosol } \\
\text { with increased relative } \\
\text { humidity }\end{array}$ & DPP4 & $\begin{array}{l}106 \text { (13.5) Saudi Arabia } \\
2013-2015^{2} \\
25(13.4) \text { South Korea } 2015^{2}\end{array}$ & Settings: hospital, dialysis unit \\
\hline SARS-CoV-2 & $\begin{array}{l}\text { URT }^{8} \\
\text { LRT }^{8} \\
\text { Feces }^{8}\end{array}$ & $\begin{array}{l}\text { Similarly stable in aerosol as } \\
\text { SARS-CoV- } 1^{9} \\
\text { Detected on hospital surfaces } \\
\text { and in aerosol samples }{ }^{10, a}\end{array}$ & ACE-2 & $\begin{array}{l}1,716 \text { (3.8) China } 2020^{6} \\
2,026 \text { (9) Italy } 2020^{7}\end{array}$ & Settings: hospital, nursing facility \\
\hline
\end{tabular}

Note. HCW, healthcare worker; URT, upper respiratory tract; URT, lower respiratory tract.

${ }^{\text {aRNA }}$ detected, not confirmed viable virus.

small droplets. Aerosol transmission can generally refer to both categories of particles. ${ }^{1}$ These terms and the exact cut-off for droplet size are controversial. Given these different routes of transmission, research regarding nosocomial transmission of emerging viruses should address the following questions: Where is viable virus shed from infected individuals? How stable is the virus on surfaces, in liquids, and within aerosols in clinical settings? Through what routes of exposure and dosages of virus does infection occur? And lastly, in what situations are nosocomial transmission events occurring? Using this framework, we can assess the risks for nosocomial transmission of emerging coronaviruses. These characteristics for SARS-CoV-1, MERS-CoV, and SARS-CoV-2 are shown in Table 1.

During the initial epidemic of SARS, many healthcare workers (HCWs) were infected, with estimates ranging from $18.8 \%$ to $57.7 \%$ of the total cases within outbreaks. ${ }^{2}$ Retrospective studies showed that SARS-CoV-1 transmission was associated with certain aerosol-generating medical procedures (AGMPs), which can either generate or induce a patient to form virus-laden aerosols. ${ }^{1}$ For SARS-CoV-1 transmission, these included cardiopulmonary resuscitation, bronchoscopy, noninvasive ventilation, intubation, and manual ventilation. ${ }^{1}$ Viable SARS-CoV-1 was found to be shed via secretions in the upper and lower respiratory tracts (URT and LRT), urine, as well as in feces from patients. ${ }^{3}$ The angiotensin-converting enzyme 2 receptor was identified as the entry point for the virus to infect cells in the respiratory tract. Therefore, it was presumed that direct and indirect contact were likely sources of transmission. Given the association with AGMPs and detection of virus in the LRT and URT, aerosol transmission was also likely, although the specific relationship of aerosol size with infection was unclear.

When MERS-CoV emerged in 2013, healthcare settings were recognized as areas of outbreak amplification and possible super-spreading events. ${ }^{2}$ Multiple cases of MERS among HCWs were linked to hospital facilities in Saudi Arabia and South Korea. ${ }^{2}$ Experimental studies of MERS-CoV found that the virus was more stable on surfaces in temperate versus tropical environmental conditions and that the stability of the virus in aerosol decreased with increasing relative humidity. ${ }^{4}$ These findings indicated that healthcare environments could be particular areas of virus persistence. MERS-CoV was detected in bodily fluids, similar to SARS-CoV-1, but MERS-CoV utilized a different host cell receptor for entry, dipeptidyl peptidase 4 (DPP4), and it predominantly replicated in the LRT, indicating potential differences in transmission. ${ }^{5}$

As reports emerged about a disease caused by a novel coronavirus in China, which became known as COVID-19 and SARS-CoV-2, respectively, nosocomial transmission was again suspected. During the initial outbreak in China, 1,716 COVID-19 cases were confirmed (3,019 suspected) among HCWs as of February 11, 2020, and some of these infections likely occurred in healthcare settings. ${ }^{6}$ Subsequently, the pandemic spread to Italy, where at least 2,026 HCW s had been confirmed to have COVID-19 as of March $15,2020 .^{7}$ As the United States became a new epicenter of the pandemic, additional infections among HCWs occurred. Similar to SARS-CoV-1, viable SARSCoV-2 was identified in the URT, LRT, and feces of patients, and SARS-CoV-2 was also found to use the ACE-2 receptor. ${ }^{8}$ Stability studies found that the virus was similarly stable to SARS-CoV-1 on surfaces and in aerosols. ${ }^{9}$ Multiple hospital surfaces and air samples were also found to be contaminated with SARS-CoV-2 RNA. ${ }^{10}$ Meanwhile, ongoing studies are evaluating where viable virus can be detected in clinical settings and whether certain medical procedures are associated with transmission. During these studies, it will be important to understand the variety of environments in different healthcare facilities. Given the similar stability of SARS-CoV-1 and SARS-CoV-2, AGMPs likely pose an increased risk for aerosol transmission of SARS-CoV-2, and healthcare surfaces could be sources of fomite transmission. As the pandemic continues to unfurl, it will be critical to identify which HCWs and patients may have been infected in clinical settings and through which route of transmission. Such research will not only allow healthcare systems to improve policies regarding PPE and decontamination procedures but will also enable risk assessment for healthcare personnel and patients. Although experiments can help us understand characteristics of emerging viruses, ultimately, multidisciplinary collaborations are required in clinical settings to elucidate and prevent nosocomial transmission. 


\section{Acknowledgments.}

Financial support. Dr Munster is supported by the Intramural Research Program of the National Institute of Allergy and Infectious Diseases, National Institutes of Health.

Conflicts of interest. The authors declare no conflicts of interest.

\section{References}

1. Judson SD, Munster VJ. Nosocomial transmission of emerging viruses via aerosol-generating medical procedures. Viruses. 2019;11:940.

2. Chowell G, Abdirizak F, Lee S, et al. Transmission characteristics of MERS and SARS in the healthcare setting: a comparative study. BMC Med 2015; 13:210.

3. Xu D, Zhang Z, Jin L, et al. Persistent shedding of viable SARS-CoV in urine and stool of SARS patients during the convalescent phase. Eur J Clin Microbiol Infect Dis 2005;24:165-171.
4. van Doremalen N, Bushmaker T, Munster V. Stability of Middle East respiratory syndrome coronavirus (MERS-CoV) under different environmental conditions. Eurosurveillance 2013;18:20590.

5. Corman VM, Albarrak AM, Omrani AS, et al. Viral shedding and antibody response in 37 patients with Middle East respiratory syndrome coronavirus infection. Clin Infect Dis 2015;62(4):civ951.

6. Wu Z, McGoogan JM. Characteristics of and important lessons from the coronavirus disease 2019 (COVID-19) outbreak in China. JAMA 2020;323: 1239-1242.

7. Livingston E, Bucher K. Coronavirus Disease 2019 (COVID-19) in Italy. JAMA 2020;323:1335.

8. Wang W, Xu Y, Gao R, et al. Detection of SARS-CoV-2 in different types of clinical specimens. JAMAh 2020;323:1843-1844.

9. van Doremalen N, Bushmaker T, Morris DH, et al. Aerosol and surface stability of SARS-CoV-2 as compared with SARS-CoV-1. N Engl J Med 2020;382:1564-1567.

10. Guo Z-D, Wang Z-Y, Zhang S-F, et al. Aerosol and surface distribution of severe acute respiratory syndrome coronavirus 2 in hospital wards, Wuhan, China, 2020. Emerg Infect Dis. 2020;26(7). doi: 10.3201/eid2607.200839.

\title{
Adverse effects of nasopharyngeal swabs: Three-dimensional printed versus commercial swabs
}

\author{
Kalpana Gupta MD, MPH ${ }^{1,2}$ (1), Pamela M. Bellino OTR/L, CPPS ${ }^{1}$ and Michael E. Charness MD ${ }^{1,2,3}$ \\ ${ }^{1}$ VA Boston Healthcare System, West Roxbury, Massachusetts, ${ }^{2}$ Boston University School of Medicine, Boston, Massachusetts and ${ }^{3} \mathrm{Harvard}$ Medical School, \\ Boston, Massachusetts
}

To the Editor-To date, $>6$ million tests for COVID-19 have been performed in the United States, with the vast majority utilizing nasopharyngeal sampling. ${ }^{1}$ The need for large-scale testing in the COVID-19 pandemic has created a global shortage of commercial nasopharyngeal swabs. One approach to this shortage has been the 3-dimensional (3D) printing of nasopharyngeal swabs. Swabs printed on a 3D printer (3D swab) differ somewhat from commercially produced swabs: they having larger heads, less flexibility, and a plastic rather than cotton or polyester fiber tip. These 3D swabs are class 1 medical devices, and their diagnostic efficacy has been validated through field testing. ${ }^{2}$

Guidance on the safe collection of nasopharyngeal samples using commercial swabs is available in text and video format ${ }^{3,4}$; however, no data are available on the adverse effects of either commercial or 3D swabs, making it difficult to assess their relative safety. To expand testing at our medical center, we printed the Northwell prototype 3D swab using specifications obtained from the technology transfer office at the University of South Florida. As part of our safety assessment of this prototype, we identified adverse effects of NP swabbing in employees using both commercial and 3D swabs. Epistaxis occurred immediately or shortly following the removal of the swab in $5.0 \%$ of employees tested with the $3 \mathrm{D}$ swab and in $8.3 \%$ of employees tested with the commercial swab (Table 1). Epistaxis was usually mild and self-limited, although 1 employee required an emergency department visit for ongoing

Author for correspondence: Kalpana Gupta, E-mail: Kalpana.gupta@va.gov Cite this article: Gupta K, Bellino PM, and Charness ME. (2021). Adverse effects of nasopharyngeal swabs: Three-dimensional printed versus commercial swabs. Infection Control \& Hospital Epidemiology, 42: 641-642, https://doi.org/10.1017/ice.2020.297
Table 1. Comparison of 3D Printed Nasopharyngeal Swabs Versus Commercial Swabs

\begin{tabular}{lcc}
\hline Variable & Commercial Swab, No. & 3D Swab, No. \\
\hline Sample size & 96 & 80 \\
\hline Epistaxis, no. (\%) & $8(8.3)$ & $4(5.0)$ \\
\hline Nasal discomfort & 4 & 6 \\
\hline Headache & 5 & 2 \\
\hline Ear discomfort & 5 & 1 \\
\hline Rhinorrhea & 5 & 1 \\
\hline
\end{tabular}

epistaxis after testing with a commercial swab. Other minor adverse effects included nasal discomfort, headache, earache, and rhinorrhea, which typically lasted hours to a day.

Our finding that epistaxis is equally common after the use of $3 \mathrm{D}$ and commercial swabs provides reassurance that $3 \mathrm{D}$ swabs are a safe alternative to commercial swabs. However, the $5 \%-10 \%$ incidence of epistaxis after nasal swabbing with either commercial or 3D swabs warrants caution in testing individuals at increased risk for bleeding. Nursing home residents have been disproportionately affected by COVID-19, and a recent point prevalence study of Medicare fee-for-service beneficiaries found that almost half of 37,787 nursing home residents were treated with oral anticoagulants. ${ }^{5}$ Rates of epistaxis after nasal swabbing should be studied in larger populations, including the elderly, and individuals at increased bleeding risk should be monitored after the procedure. Fortunately, less invasive methods of SARS-CoV-2 